\title{
Private Sector Investment on Renewable Energy Utilization in Developing Countries
}

\author{
Alireza Aslani ${ }^{1,2, *}$ \\ ${ }^{1}$ Industrial Management Department, Faculty of Technology, University of Vaasa, P.O. Box 70065101 \\ Vaasa, Finland \\ ${ }^{2}$ Invited Scholar in the Department of Mechanical and Aerospace Engineering, College of Engineering, \\ University of Miami, Miami, FL 33146, USA
}

\begin{abstract}
Feasibility potentials in the Middle East and Iran offer many opportunities for private sector investment in renewable energy industry. However, due to the high primary investment costs in this technology, as well as dominate role of fossil fuels in the Middle East, promotion plans cannot be achieved without government incentives and supports. First, this article tries to answer to one of the main questions of private investors related to identification of the most important renewable source for investment in Iran. Then, to success implementation of investment and government plans, different polices and support schemes of the Nordic countries as successful countries in adoption of renewables are reviewed and discussed.
\end{abstract}

Keywords: Renewable Energy, Investment, Private Sector, Developing Countries, Nordic region.

\section{INTRODUCTION}

Today one of the important factors of world's energy production systems is security of energy supply. Energy security concerns along with consumption growth are rapidly rising in importance for both developed and developing countries. In response, electricity/heat generation from renewable energy resources (RER) is an option that contributes dependency reduction on imported energy and provides social and environmental benefits. As renewable energy (RE) utilization is usually developed in local areas, it brings social welfare and unemployment decrease in rural regions.

Despite progresses on RE utilization in the last decades, Middle Eastern countries have not been successful in diffusion and adaption of these technologies compered to developed countries. For instance, despite Iran is known as a rich country in terms of RERs, the main and dominant conventions of resources are hydrocarbon. According to EIA reports, carbon-based resources are supplying more than $97 \%$ of primary energy, in which the share of electricity generation is around 93\% [1]. Indeed, electricity demand is growing between 7-10 percent annually in Iran, faster than the global average. The resultant, while the country is the third largest producer of natural gas in the world, it imported gas even for domestic usages in some years [2]. Therefore,

*Address correspondence to this author at the Industrial Management Department, Faculty of Technology, University of Vaasa, P.O. Box 70065101 Vaasa, Finland; Tel/Fax: +358 44255 0010; E-mail: alireza.aslani@uva.fi challenges exist for Iranian energy policy -makers in optimal utilization of hydrocarbon resources and diffusion of RER utilization [3].

Due to the rich and diversified potential of RE in Iran, development of RE utilization as cleaner energy resources is one of the suggested strategies to minimize the fossil fuel usage and reduce the environmental footprints [4]. However, most of the energy market in Iran is under dominance of government and private sector has not a clear role in RE utilization. The statistics show that only $38 \%$ of the goals of Iran's fourth national development plan in RE have been achieved in Iran [5].

This research reviews prioritization of RERs for investment in Iran. To provide a practical viewpoint, different policies and support schemes implemented in a successful case (Nordic region) are reviewed and discussed.

The article is organized as follows: Section 2 gives a brief review of $R E$ potentials in Iran. Section 3 reviews current public policies toward diffusion of $R E$ in Iran. Section 4 presents the prime criteria for private sector participation in RE investment. Section 5 prioritizes the main RE sources based on the identified criteria. Finally, section 6 discusses about a successful case in RE development. Different policies and support schemes are considered in two strategic and practical levels.

\section{POTENTIALS OF RENEWABLES IN IRAN}

As Iran is located on the world's Sun Belt, the total absorption of solar radiation is estimated between 1800 


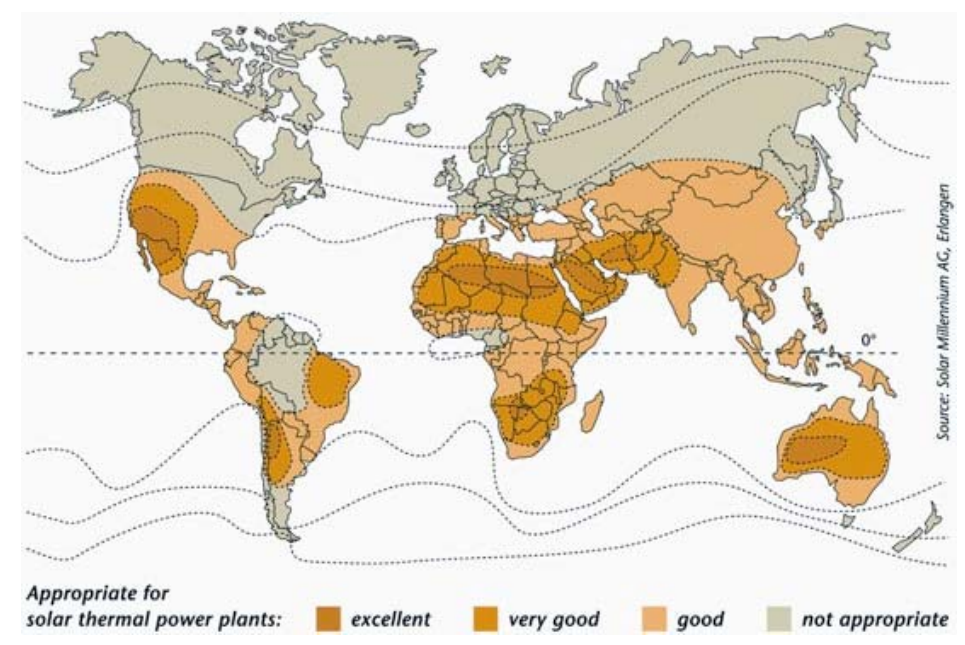

Figure 1: World sun rising [8].

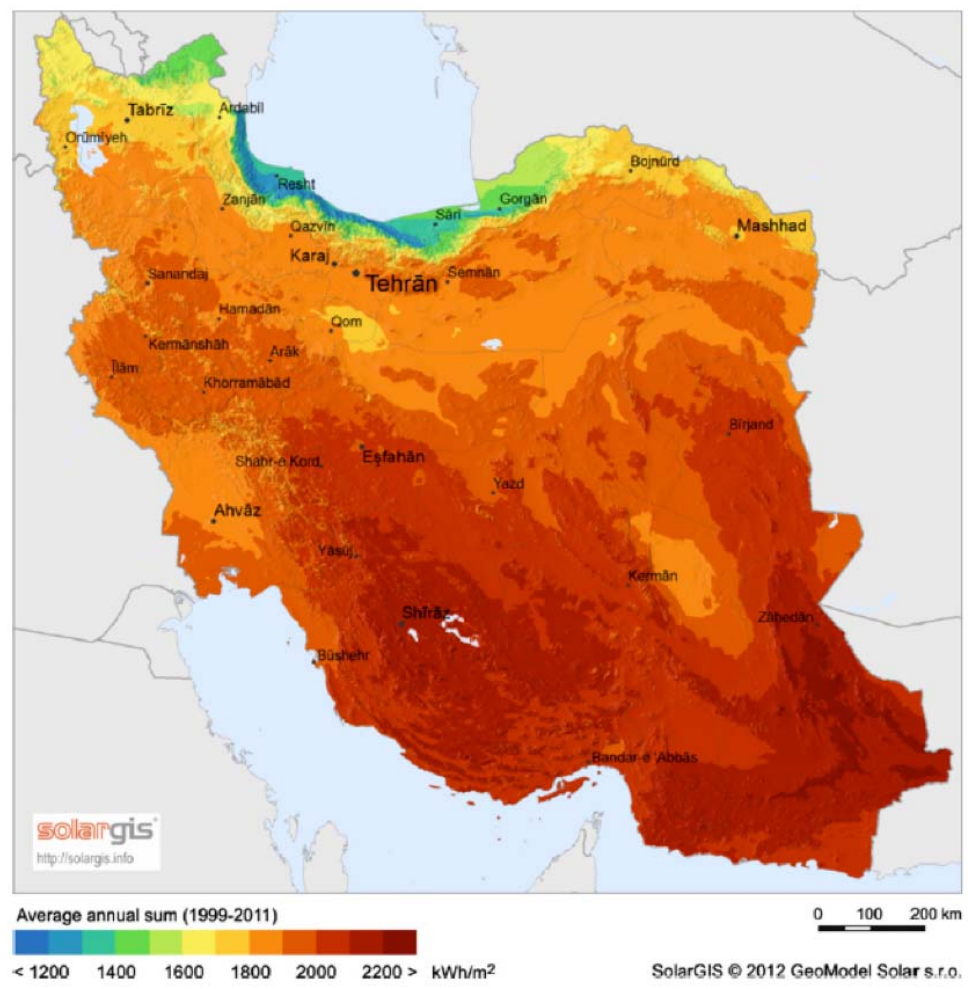

Figure 2: Iran solar energy map [9].

and 2200 kW.h.m ${ }^{-2}$ per year (higher than global average) with 280 sunny days per year (Figures 1 and 2) $[6,7]$.

Table 1 shows the total electricity generation from solar power plants in Iran in the three selected years [10].

Rain and snowfall in mountains as well as water flow in steep slopes of rivers are prime energy resources for hydro power plants in Iran. The potential of electricity generation by Hydropower in Iran is around 50TWH (Figure 3) [11]. The production capability of hydroelectricity is more than $30 \mathrm{GW}$ [12]. By the end of 2007, total installed capacity of hydroelectric power plants was 7422.5 MW in Iran [13].

There are 45 suitable sites for wind power utilization in Iran. The capacities are approximately expected $6500 \mathrm{MW}$, employing wind turbines of $60,000 \mathrm{MW}$ nominal powers [10]. The estimated capacity factor of these wind parks is around $33 \%$. Variation of wind speed potential in different sites is represented in Figure 4 [14]. 
Table 1: Electricity Generation from Solar Power Plants in Iran [10]

\begin{tabular}{|c|c|c|c|}
\hline Year & 30 kW photovoltaic (MWh) & Power plant (MWh) & Total (MWh) \\
\hline \hline 2004 & 45 & 92.2 & 137.2 \\
\hline 2006 & 42 & 37 & 79 \\
\hline 2008 & 35 & 40 & 75 \\
\hline 2010 & 32 & 35 & 67 \\
\hline
\end{tabular}

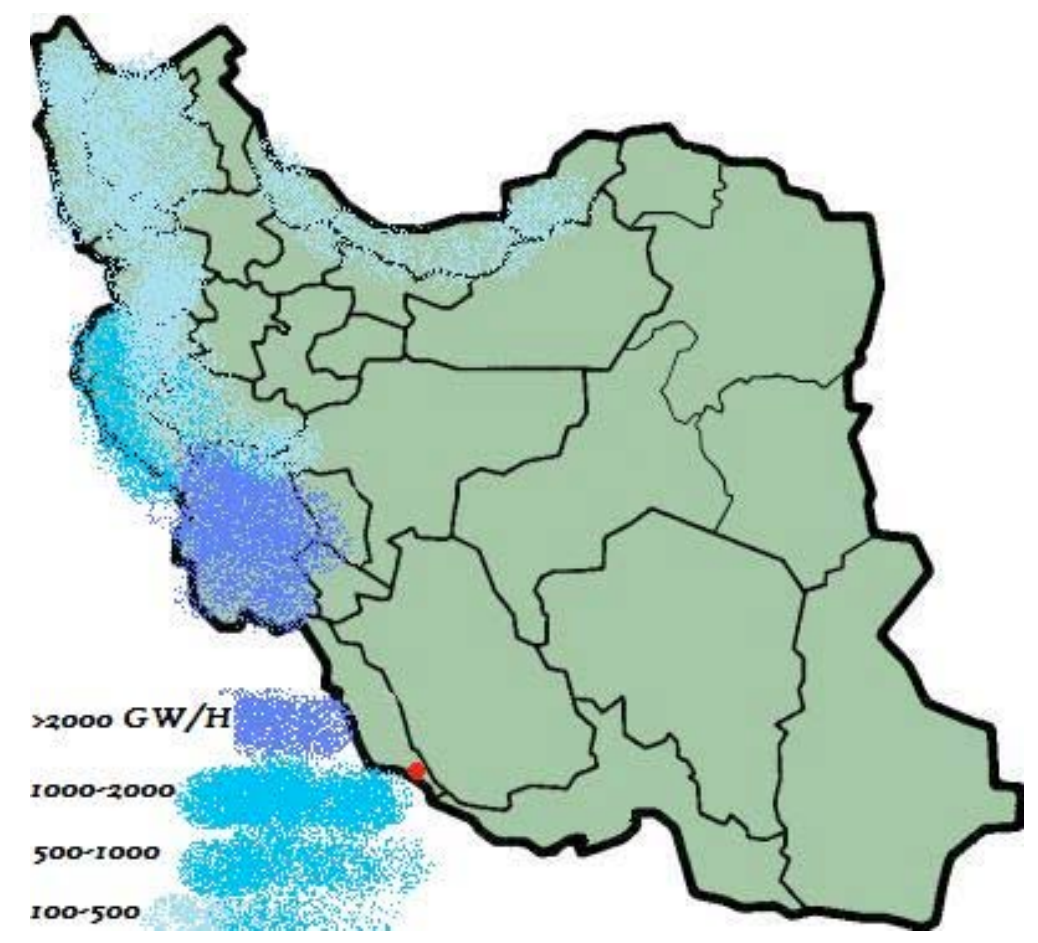

Figure 3: Iran hydropower energy map [7].

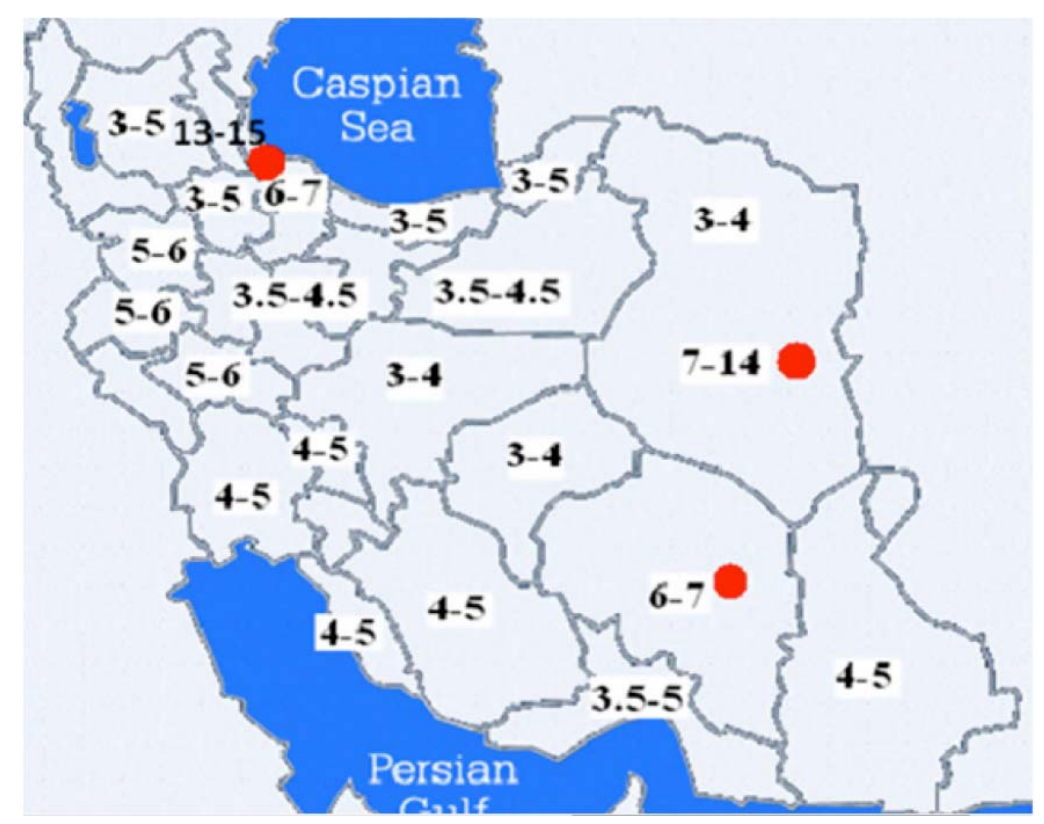

Figure 4: Variation of wind speed potential in different site in $\mathrm{m} / \mathrm{s}$ [14]. 


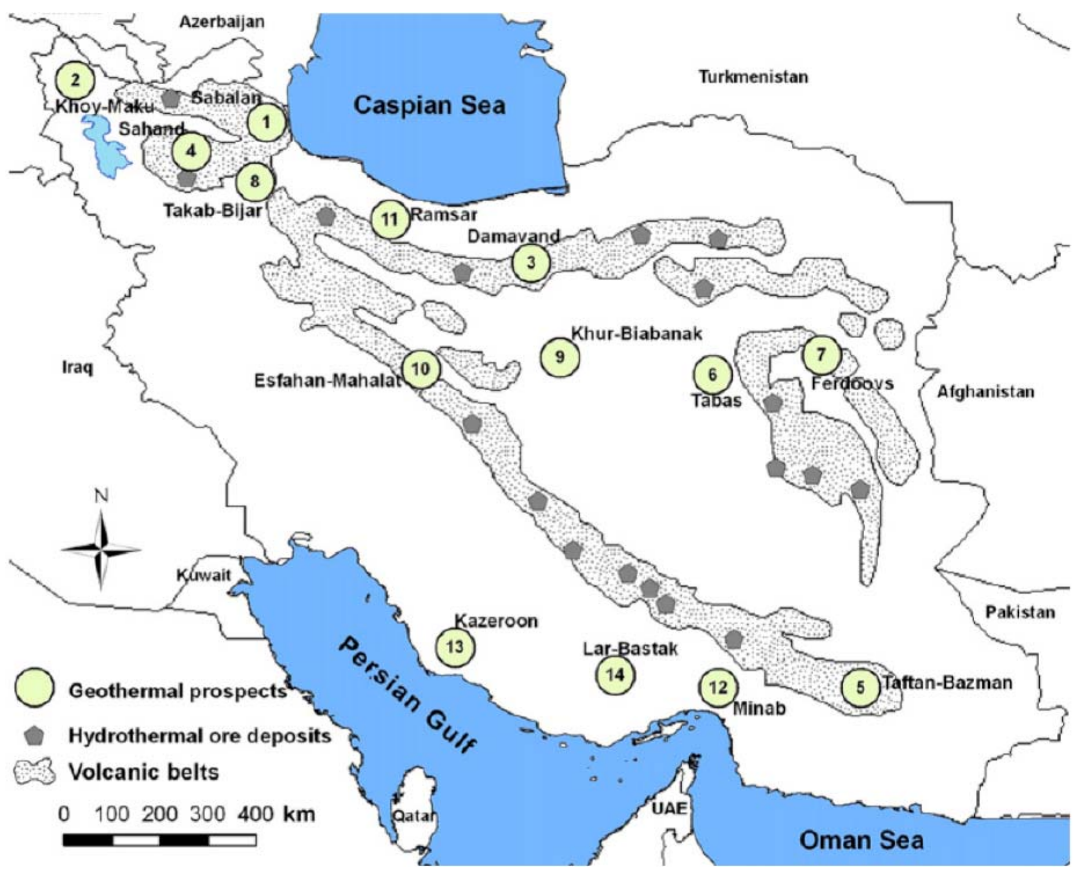

Figure 5: Geothermal energy resource in Iran [15].

Geothermal energy may be exploited in two ways in Iran: power plant generation, and off-plant utilization. Since Iran is located on the global geothermal belt, there are five main major geological places for this resources including 1. Zagros, 2, Sanandaj-Sirjan, 3. Central Iran, 4. East and South East Zone, and 5. Alborz (Figure 5).

Share of biomass waste potential energy in Iran is around $40 \%$ for animal wastes, $45 \%$ for agricultural wastes, and $15 \%$ for municipal wastes. The nameplate capacity of biogas power plants in Iran is $1860 \mathrm{KW}$ and the total installed capacity is $1665 \mathrm{~kW}$ with $5967 \mathrm{GWh}$ total Gross generation [10]. Figure 6. Shows the places of main biomass potentials in Iran.

\section{PUBLIC POLICIES TOWARD DIFFUSION OF RENEWABLE ENERGY IN IRAN}

Policy instruments are the tools that governments use to implement their public policy objectives. Iranian

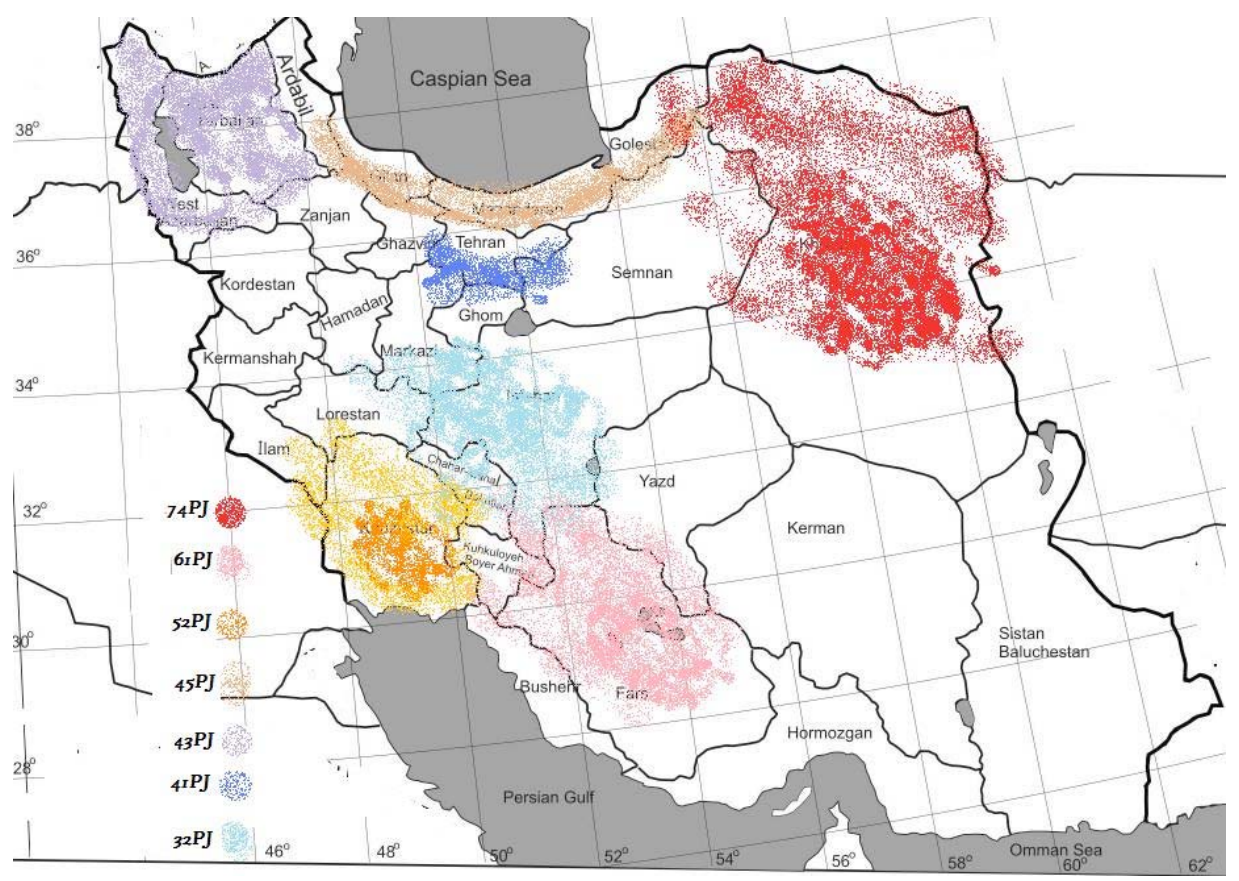

Figure 6: Iran hydropower energy map [7]. 


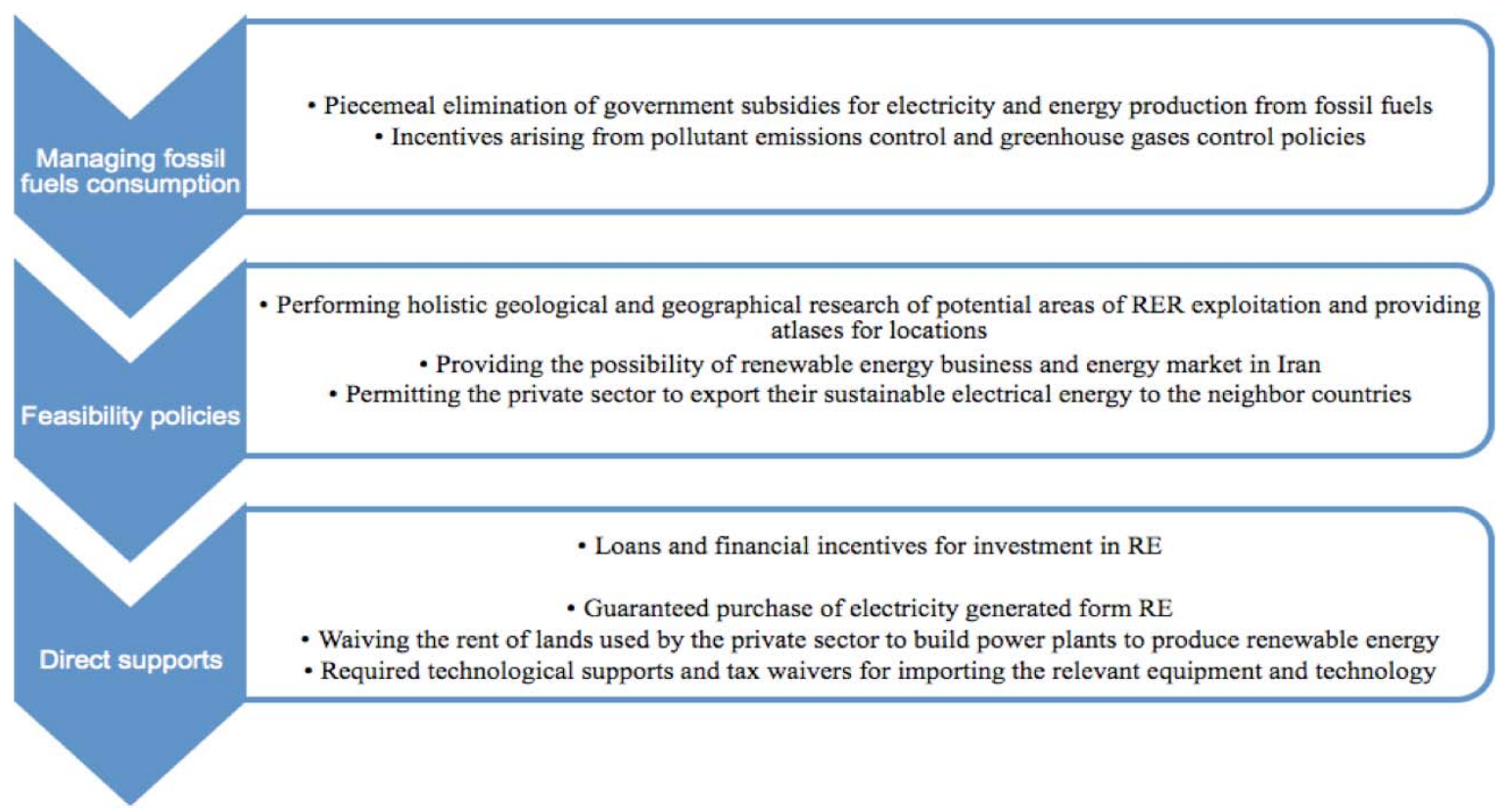

Figure 7: Government encouragement packages of RE development [17].

Ministry of Power is the responsible ministry for diffusion of RE development in Iran. It has tried to encourage the participation of private sector by providing different policies and regulations. Further, due to the situation of energy consumption in Iran and potentials of RERs, it has established an independent research and development organization called Renewable Energy Organization of Iran (SUNA) with the help of World Bank [16]. Figure 7 illustrates the important government policies related to diffusion of $\mathrm{RE}$ especially to encourage investments in Iran [17].

\section{PRIME CRITERIA FOR PRIVATE SECTOR PARTICIPATION IN RENEWABLE ENERGY INVESTMENT}

Studies show that there are important criteria for participation of private sector in RE utilization (Figure 8) [17]. The first and important factor is energy efficiency that is categorized in two different levels: efficiency in products and services, and efficiency in energy basis. More efficiency leads to the further attraction in consumption and consequently more attraction in investment.

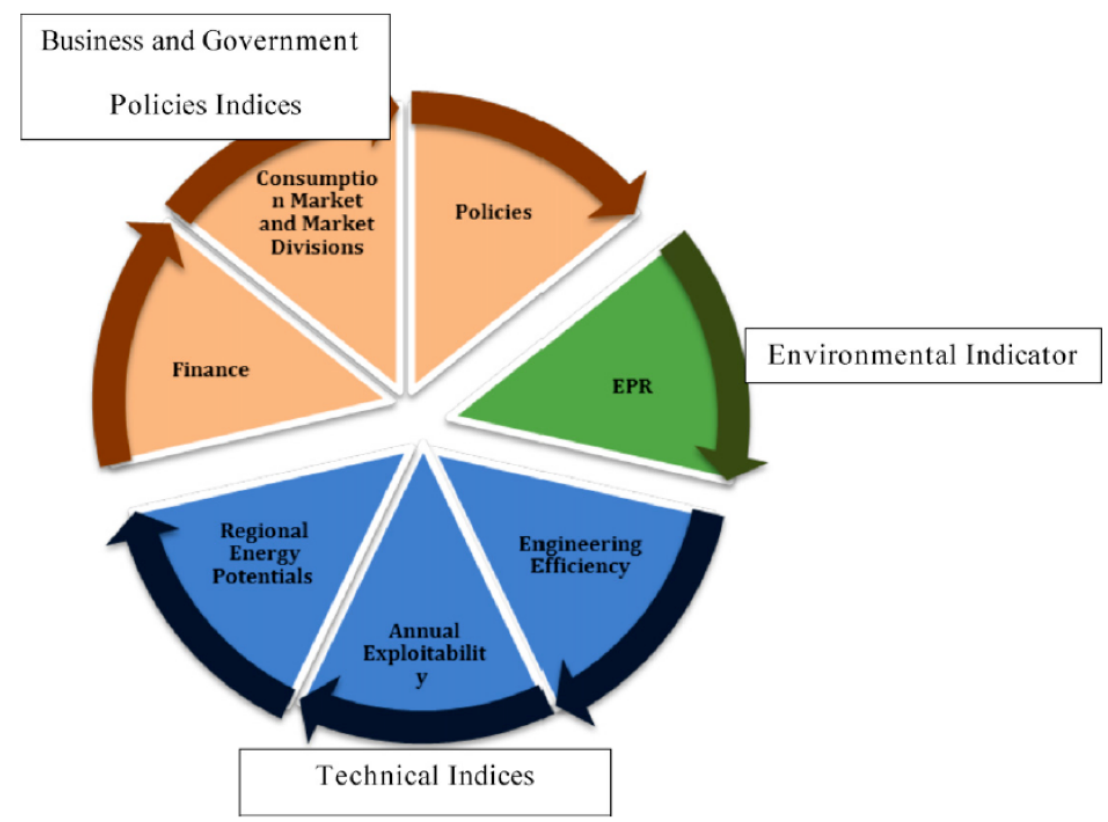

Figure 8: The identified criteria to participation of private sector [17]. 
Indeed, one of the concerns of investors in commerce of a business is the period that a product or service can be efficiently exploited [18]. Hence, investor's awareness about the accessibility and annual exploitability of RE is an important factor to evaluate the sub-indices such as investments return index, operation risk etc. On the other hand, energy resources are always considered as a constraint that may even endanger a business from competitiveness viewpoint. Therefore, the number of regions that $R E$ sources can be utilized is more attraction for investment from investor's viewpoint (Figure 5). This assumption would be considered from different aspects that the most important one is distribution and harvesting potentials.

Since one of the main interests of investors is to minimize the costs of RE generation, introducing an index for indicating required investment of each type of $\mathrm{RE}$ is important for private sector. According to Sardianou, a large number of calculations are necessary for estimating an investment's profitability that investors would like to now before they decide to invest in energy industry [19]. Because RE technologies will improve with time, financial investment of RE (project costs) generally gets cheaper.

As end-user markets provide more advantage compare to mediator markets for suppliers, they are important interests of private sector [20]. The crucial issue in consumer market is advantage-cost of a product or service. To encourage an end user to purchase a new product, they should be satisfied with what they pay compare to what they obtain.

The supportive governmental policies for investing on RE is also another important factor. In other words, accredited degree of government to $R E$ projects is important from investor viewpoint. The Iranian governmental policy seems to incentivize the private sector to invest in this area especially in some RE sources [24].
Finally, one of the main factors of RE investors for investment in energy sector is the environmental performance of RE that called Energy Payback Ratio (EPR) [21]. The factor is important from customer demands (market and consumer psychology), sustainability, and possible future rules.

\section{PRIORITIZATION OF RENEWABLE ENERGY RESOURCES FOR INVESTMENT IN IRAN}

Due to the important criteria of RE investment, the next step is identifying the most important criteria for investment. In other words, identification of the best RE sources from five common RE sources (alternatives) is the first aim. To analyze, evaluate, compare, and rank alternatives, the analytic hierarchy process (AHP) was used as one of the best and valid methods of multi attribute decision-making (MADM) [22]. 31 samples from 14 companies were randomly selected to compare and prioritize each couple of criteria, and criteria with each alternative. To analyze data, Expert Choice11 software was used. After calculating all priorities and inconsistency indices, the relative weight of each RE source for each criteria were determined. The result of RE sources in each criteria and overall result are shown in the Table 2. As table shows, solar energy is the best source for private sector investment in Iran. Wind energy is the second important source for investment in Iran.

\section{LESSONS FROM A SUCCESSFUL CASE FOR DIFFUSION OF RENEWABLE ENERGY DEVELOPMENT IN IRAN}

After identifying the priority of RERs for utilization in Iran, we study and compare a successful case in promotion and adoption of RE in order to be followed by Iran and other Middle Eastern countries. The Nordic countries including Finland, Sweden, Norway, Denmark, and Iceland are good examples for development of RE portfolios [23]. In 2011, the average utilization of RER for electricity generation in this region was $62.82 \%$ and Norway and Iceland are among top 10 renewable electricity producers with $96.6 \%$ and

Table 2: Ranks of each RE Source in each Criteria and Overall

\begin{tabular}{|c|c|c|c|c|c|c|c|c|}
\hline & Overall & Efficiency & Exploitability & Regional & Finance & Market & Supports & EPR \\
\hline \hline Solar & 1 & 4 & 2 & 1 & 1 & 1 & 1 & 4 \\
\hline Hydro power & 3 & 1 & 3 & 5 & 4 & 5 & 3 \\
\hline Wind power & 2 & 2 & 5 & 4 & 3 & 2 & 2 & 2 \\
\hline Geothermal & 4 & 3 & 1 & 3 & 5 & 3 & 5 \\
\hline Biomass & 5 & 5 & 4 & 2 & 2 & 4 & 4 \\
\hline
\end{tabular}




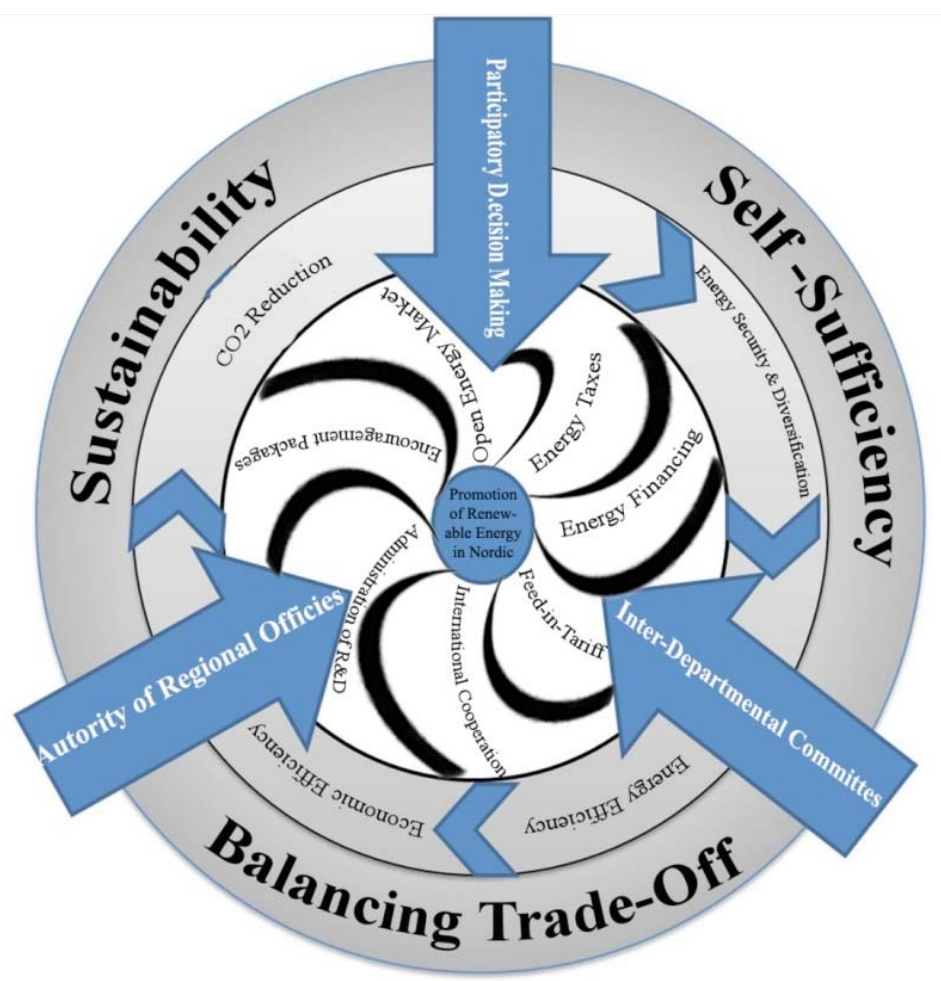

Figure 9: Layers of RE development in the Nordic countries and Finland [26].

$100 \%$ of their electricity generation from RER in the world [23].

Our studies show that in terms of diversification policies and RE promotion, Nordic countries are one of the best case studies to be followed by other countries and regions. For instance, Finland and Sweden are two of the leading bioenergy-using countries in the world [28]. In addition, Norway with hydropower development, Denmark with high growth in wind power utilization, and Iceland as a successful country in geothermal utilization are very famous in RE studies.

To understand the success of Nordic countries, we have identified different layers of RE development in this region (Figure 9) [25]. These layers create a portfolio of political, technological, managerial, social, and cultural issues. Table $\mathbf{3}$ summarized each layer and their related supporting schemes that should be considered by policy makers in Iran to have a successful RE promotion programs [26].

On the other hand and beyond the strategic issues, development and performance of renewables are highly dependent to successful implementation of RE supply chain in the regional level [27]. In other words, different practical aspects of RE utilization should be considered in order to have a successful utilization of RER in Iran (Figure 10).
According to Figure 10, the practical issues of successful RE programs (RE supply chain) are characterized from two sides: domains and approaches. The domains cover the process of RE chain from resources to end-users for each source. They create opportunities for business activities and introduced in five main domains [27].

The approaches of RE supply chain show different aspects of RE supply chain process from engineering, social, and management science. They cover all necessary elements of supply chain management. The first approach, policies and strategies, takes into account the role of municipalities and government on diffusion of $R E$ in the region. Creating a development road map for each domain of $R E$ chain, as well as introducing supportive schemes (e.g., subsidies and taxes) are two subjects that are discussed in this approach. The approach "Technology" examines the ways to provide a successful use of RERs in the region. Evaluation and analysis of region's potentials in each domain from technological and infrastructure viewpoints are the focuses of this approach. "Networks and implementation" presents, analyzes, and designs high efficient performance of RE domains. Creating better value for customers and shareholders in each RE domains, quality of RE services, joint investments, and knowledge sharing with other regions are examples of this approach [26]. Finally, 
Table 3: Different Layers of Strategic Analysis of Diffusion of Renewable Energy in the Nordic Countries [26]

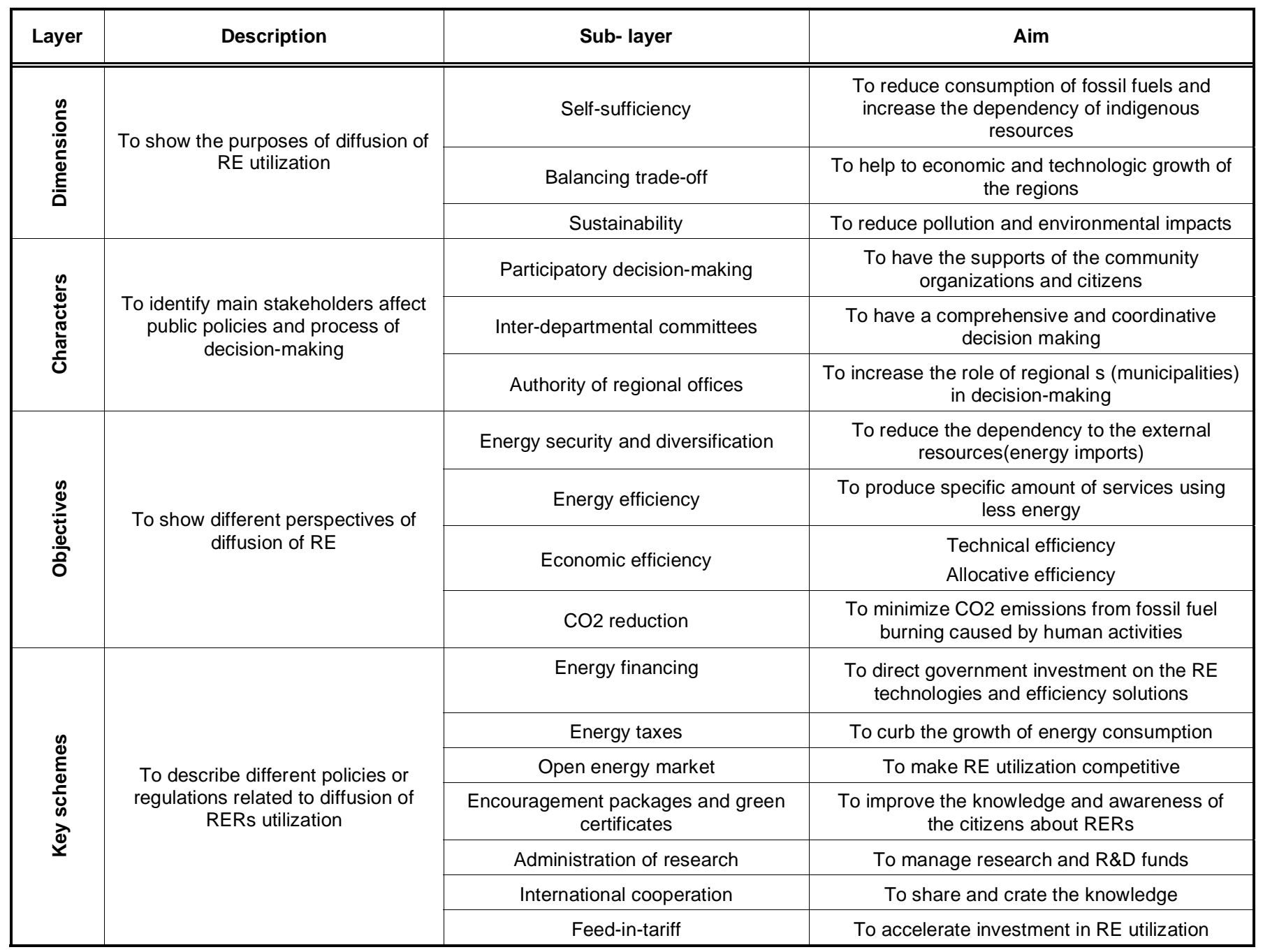

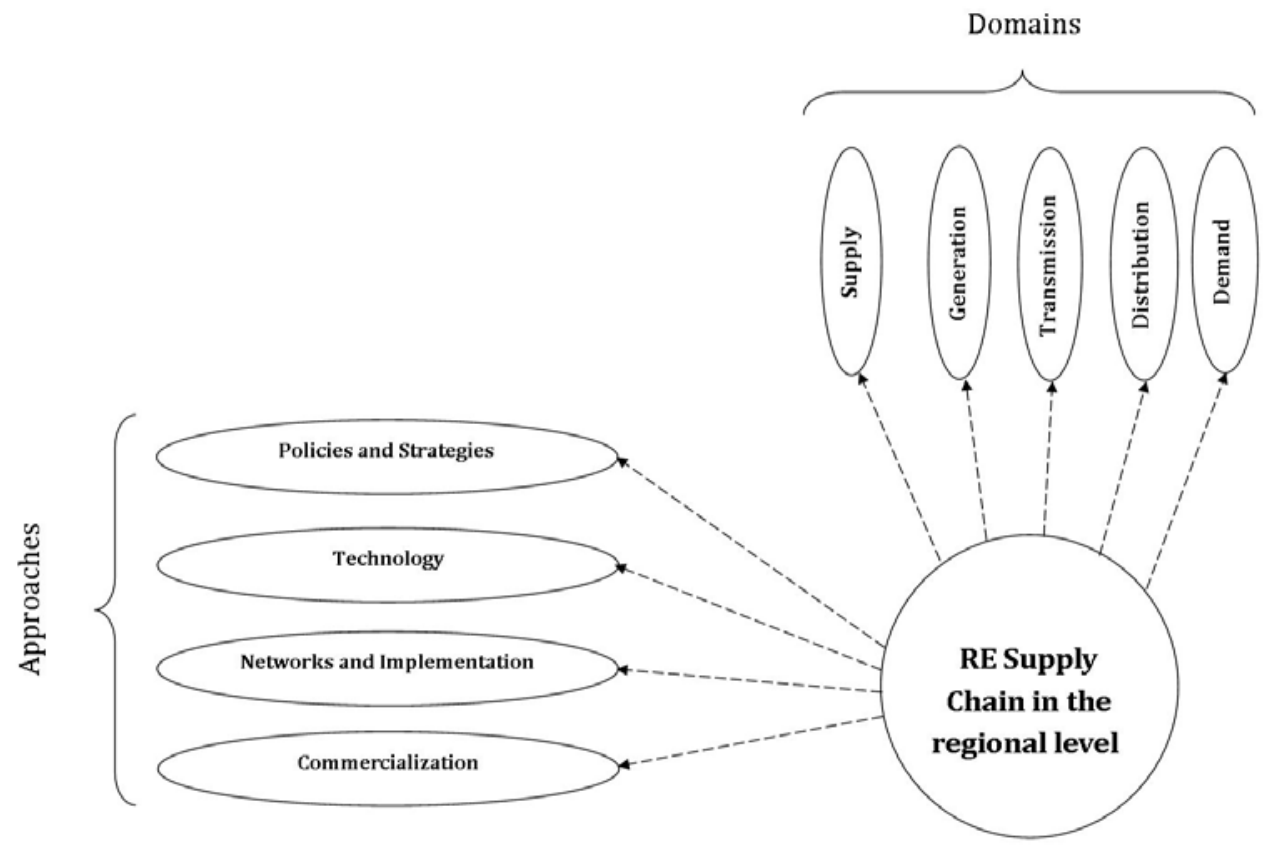

Figure 10: Framework of RE supply chain [27]. 
"commercialization" includes the economic and investment issues of RE development in the region. Studies show that RE market is complex. While Iran has not a free energy market, it should be encouraged like successful cases in the Nordic region. However, the government intervention or incentives should still support new technologies and businesses in this market.

\section{DISCUSSION AND CONCLUSIONS}

Increasing world demand for energy, fluctuating carbon based fuel prices, uncertain oil and gas supplies arising from geopolitical concerns, and global warming have caused developed and developing countries to have the secure and safe supply of energy by RE utilization. Despite high potential, promotion and adoption of renewable energy sources are very slow due to excessive concentration of fossil resources in the Middle East and Iran. To have a success utilization of $R E$, related industries need to be competitive and be subsequently non-government. Therefore, participation of private sector is the main deriver engine of $R E$ development in developing countries. On the other hand, as economics of renewables are not competitive because of installation costs per unit of energy, government supply and financing is essential, particularly for developing countries.

This article reviewed important RERs and prioritized them based on investor's needs and concerns in Iran. Thereby, the solar energy was introduced as the best RE source for private investment and even in the Middle East. After solar, wind power and hydropower sources are in the second and third priorities for investment in Iran. To provide an action plan and executive road map, the strategic and practical factors and polices of a successful case were studied and compared.

As there are several options for renewable energy development in Iran and other developing countries such as generating energy in off-grid and rural power plants, cooking at scale with solar, powering mobile telephone masts by using solar energy, and converting different categories of waste to energy, the potential of each source and option can be discussed and studies for future researches.

\section{ACKNOWLEDGEMENTS}

The Author offers his sincere thanks to all those contributed by their instructions and also who responded the questionnaire in particular the investors, and experts and researchers of the Iranian Ministry of Energy, and Iranian Ministry of Science and Technology.

\section{REFERENCES}

[1] EIA International Energy Annual 2007, http://www.eia.gov/ countries/cab.cfm?fips=IR ; [01.10.2013].

[2] BP Statistical Review of World Energy, 2010. Available from: http://www.bp.com/liveassets/bp_internet/globalbp/globalbp_ uk_english/reports_and_publications/statistical_energy_revie w_2008/STAGING/local_assets/2010_downloads/statistical_r eview_of_world_energy_full_report_2010.pdf; [01.10.2013].

[3] Ghazinoory S, Huisingh D. National program for cleaner production (CP) in Iran: a framework and draft. J Clean Produc 2006; 14.

[4] Mousavi-Avval SH, Rafiee S. Energy flow modeling and sensitivity analysis of inputs for canola production in Iran. $J$ Clean Produc 2011; 19

[5] Fadai D, Esfandabadi ZSh. Analyzing the Causes of nonDevelopment of Renewable Energy-Related industries in Iran. Renewable Sustainable Energy Rev J 2011; 15.

[6] Iran Renewable Energy Organization (SUNA), Biomass Energy, http://www.suna.org.ir/ationoffice-zisttoodehofficezisttoudehenergy-fa.html; [01.10.2013].

[7] Energy Balance Sheet, Department of Electrical and Energy Department of Energy Ministry 2007.

[8] Eu Solar Thermal electricity Association, Available from: http://www.google.com/imgres?um =1\&hl=en\&lr=\&biw=1280\& bih=685\&tbm=isch\&tbnid=wNTqBPibJjP1eM:\&imgrefurl=http: //www.estelasolar.eu/index.php\%3Fid\%3D18\&docid=fSH7pxYbbB2MM\&imgurl=http://www.estelasolar.eu/uploads/pics/ map.jpg \&w=340\& $\mathrm{h}=274 \& \mathrm{e}=\mathrm{mWW}$ - $\mathrm{w}$ sqED6Pj4QT9p9GPBA $\& z o o m=1$; [01.10.2013].

[9] Maps of Global horizontal irradiation, Solar GIS@2013 Geo Model Solars. r.o. Available from: 〈http://solargis.info/doc/71〉

[10] Bahrami M, Abbas P. zadeh/Renewable Sustainable Energy Rev 2013; 24: 198-208. http://dx.doi.org/10.1016/j.rser.2013.03.043

[11] Supersberger N. Energy Systems in OPEC Countries of the Middle East and North Africa, Wuppertal Institute, 2009 http://personal.Ise.ac.uk/kumetat/pdfs/OPEC-EnergySystems_report.pdf; [01.10.2013].

[12] Iran Renewable Energy Organization (SUNA), Solar Energy http://www.suna.org.ir/ationoffice-sunenergyofficesolarenergy-fa.html; [01.10.2013].

[13] Energy Balance Sheet, Department of Electrical and Energy Department of Energy Ministry 2007.

[14] Najafi Gh, Ghobadian B. LLK1694-wind energy resources and development in Iran. Renewable Sustainable Energy Rev 2011; 15: 2719-28.

[15] Yousefi H, Noorollahi Y, Ehara S, Itoi R, Yousefi A, Fujimitsu $Y$. Developing the geothermal resources map of Iran. Geothermics 2010; 39: 140-51. http://dx.doi.org/10.1016/i.geothermics.2009.11.001

[16] Iran Renewable Energy Organization (SUNA), http://www. suna.org.ir/home-en.html; [01.10.2013].

[17] Aslani A, Naaranoja M, Zakeri B. The Prime Criteria for Private Sector Participation in Renewable Energy Investment in the Middle East. Renewable Sustainable Energy Rev J 2012; 16(4): 1977-87.

http://dx.doi.org/10.1016/j.rser.2011.12.015

[18] Aslani A, Feng B. Investment prioritization in renewable energy resources with consideration to the investment criteria. Distributed Generation and Alter- native Energy Journal in press. 
[19] Sardianou E. Barriers to industrial energy efficiency investments in Greece. J Clean Produc 2008; 16.

[20] Atabi F. Renewable energy in Iran: Challenges and opportunities for sustainable development. Int J Environ Sci Technol 2004; 1(1).

[21] Burcher S, Lim LC. Food Future Now, Organic, Sustainable Fossil Fuel Free, ISIS \& TWN, London 2008.

[22] Dong Jun K. Development of an assessment model using AHP Techniques for Railroad Projects Experiencing Server Conflicts in Korea. Proceedings of the Eastern Asia Society for Transportation Studies 2005; 5.

[23] Aslani A, Antila E, Wong KF, Aslani A, Antila E, Wong KF. Comparative analysis of energy security in the Nordic countries: the role of renewable energy resources in diversification. J Renewable Sustainable Energy 2012; 4(6). http://dx.doi.org/10.1063/1.4765695

[24] Aslani A. Private sector investment in renewable energy utilization: strategic analysis of stakeholder perspectives in developing countries. Int J Sustainable Energy, in press. http://dx.doi.org/10.1080/14786451.2012.751916
[25] Zuluaga MM, Dyner I. Incentives for renewable energy in reformed Latin American electricity markets: the Colombian case. J Clean Produc 2007; 15.

[26] Aslani A, Naaranoja M, Wong KF. Strategic analysis of diffusion of renewable energy in the Nordic countries. Renewable Sustainable Energy Rev 2013; 22: 497-505. http://dx.doi.org/10.1016/j.rser.2013.01.060

[27] Aslani A, Help P, Feng B, Antila E, Hiltunen E. Renewable energy supply chain in Ostrobothnia region and Vaasa city: Innovative framework. Renewable Sustainable Energy Rev 2013; 23: 405-11. http://dx.doi.org/10.1016/j.rser.2013.03.012

[28] Aslani A, Naaranoja M, Helo P, Antila E, Hiltunen E. Energy diversification in Finland: achievements and potential of renewable energy development. Int J Sustainable Energy, in press.

http://dx.doi.org/10.1080/14786451.2013.766612 